\title{
In vitro characterization and in vivo performance of mefenamic acid-sodium diethyldithiocarbamate based liposomes
}

\author{
Qais Bashir Jarrar', Muhammad Nazrul Hakim,1, Manraj Singh Cheema ${ }^{\circledR}$, \\ Zainul Amiruddin Zakaria ${ }^{1}$ \\ Department of Biomedical Sciences, Faculty of Medicine and Health Sciences, Universiti Putra Malaysia (UPM), Serdang, \\ Selangor, Malaysia
}

\begin{abstract}
Mefenamic acid (MFA) is a hydrophobic drug with low dissolution rate. This study aimed to develop stable and reproducible aqueous formulations of MFA using liposomes as drug carriers. The drug entrapment, particles size and drug release profiles, and stability and reproducibility of the liposomes were determined. In addition, the maximum tolerated dose (MTD) was determined in rats via the oral and intraperitoneal routes of administration. Also, the anti-inflammatory efficacy of these liposomes was evaluated using carrageenan-induced paw edema model in rats. MFA-DDC based liposomes demonstrated a drug entrapment efficacy of $93.6 \%$, particles size of $170.9 \mathrm{~nm}$, and polydispersity index of 0.24 which were not statistically affected when stored in room and refrigerated temperatures for at least 4 weeks. The MTD of the intraperitoneally administrated MFA-loaded liposomes was $20 \mathrm{mg} \mathrm{MFA} / \mathrm{kg}$, whereas for those of oral administrations, it was up to $80 \mathrm{mg} \mathrm{MFA} / \mathrm{kg}$. Intraperitoneal dose $(80 \mathrm{mg} \mathrm{MFA} / \mathrm{kg})$ of MFA-DDC liposomes induced extrapyramidal symptoms associated with significant elevation in serum potassium and muscle enzymes. Moreover, significant inhibition of paw edema was demonstrated by the oral and intraperitoneal routes. These findings suggest that MFA-DDC based liposomes are an effective formulation of MFA and recommend the use of bioequivalence assessments with commercial formulations.
\end{abstract}

Keywords: Mefenamic acid. Liposomes-characterization. Sodium diethyldithiocarbamate. Extrapyramidal symptoms. Carrageenan.

\section{INTRODUCTION}

Mefenamic acid (MFA) is a member of NSAIDs which poses anti-inflammatory, anti-nociceptive, and antipyretic properties (Cimolai, 2013). According to the biopharmaceutical classification system, this drug belongs to class II drugs which are characterized by poor water solubility and low dissolution rate (Abdul Mudalip et al., 2013). The insufficient solubility of MFA usually results in poor bioavailability and gives suboptimaltherapeutic responses. Considerable efforts have been given to enhance MFA water solubility as a key element in improving its bioavailability with little progress (Abdul Mudalip et al., 2013; Imai et al., 1991).

\footnotetext{
*Correspondence: M. N. Hakim. Department of Biomedical Sciences, Faculty of Medicine and Health Sciences, Universiti Putra Malaysia (UPM), 43400 Serdang, Selangor, Malaysia. Mobile: 0060193883845 . E-mail: nazrulh@upm.edu.my
}

Liposomes are drug nanocarriers which basically consist of phospholipids bilayer (s) and pose amphiphilic nature that allows entrapping both hydrophilic and hydrophobic drugs and exhibits multiple biopharmaceutical functions (Bozzuto, Molinari, 2015). Liposomes can enhance drugs solubility, improve bioavailability, and protect the entrapped drug from enzymatic degradation (Bozzuto, Molinari, 2015; Kim, Kim Lee, 2013). Moreover, liposomes provide sustained drug release, enhance drug cellular uptake, allow specific tissue targeting, and delay drug clearance (Fricker et al., 2010). However, the in vivo performance of the liposomes depends extensively on their physicochemical properties including their chemical constituents, drug entrapment capacity, size profiles, liposome surface charge, $\mathrm{pH}$ sensitivity, and drug release properties (Gatoo et al., 2014). Determining the in vitro characteristics of liposomes constitutes a basic requirement for prediction the in vivo performance of the liposomes and selection 
of the most suited route of administration. Methods used in liposomes preparation differ in their ability to scale up liposomes production (Wagner, Vorauer-Uhl, 2010). Also, these methods yield liposomes of different encapsulation efficacy, particles size, and shelf lives stability.

Sodium diethyl dithiocarbamate (DDC), the main metabolite of disulfiram, has been used in a combination therapy with NSAIDs to improve their therapeutic efficacy and reduce their toxicity due to the wide spectrum of pharmacodynamic activities and unique properties (Lai, Wang, 2002). It is utilized in metals chelating, free radicals scavenging, and modification of liver enzyme metabolism. These together, enable DDC to restore the immune functions, regulate the inflammatory responses, exert anti-inflammatory properties, work as an antidote for drug poisonings, inhibit the progression of AIDS and fungal infections, and kill various types of neoplastic cells (Martinez-Martinez et al., 1997).

Mefenamic acid-sodium diethyldithiocarbamate based liposomes (MFA-DDC based liposomes) were recently prepared in our laboratory. The present work aimed to evaluate the efficacy and toxicity of these liposomes via different routes of administration.

\section{MATERIAL AND METHODS}

\section{Reagents}

All chemicals and reagents used in this study were of analytical grade and used without further purification. Pure MFA powder and sodium diethyldithiocarbamate (DDC) were purchased from Sigma-Aldrich (The United States), dimethyl sulfoxide (DMSO) 99.5\% from Sigma Life Science (The United States), and Univar (France), Pro-Lipo Duo from Lucas Meyer France.

\section{Preparation of MFA-DDC based liposomes}

Mefenamic acid-DDC based liposomes were prepared from a commercial phospholipids mixture (Pro-lipo duo ${ }^{\circledR}$ ) according to the manufacturer's (Lucas Mayer, France) instructions with some modifications. Briefly, a drug solution was prepared by dissolving an equivalent amount of MFA and DDC (100 mg each) in DMSO. The drug solution was then added to Pro-Lipo Duo and mixed on a magnetic stirrer at moderate speed (100 RPM) for 1 hour. Next, the mixture was gradually hydrated with Tween 20 aqueous solution $(0.004 \% \mathrm{w} / \mathrm{w})$ and continuously mixed for a predetermined period 1 , 5 or 10 hour(s). Following hydration, the concentrated liposomal dispersion was diluted with ultra-purified water and mixed for another 30 minutes. In all formulations, the ratio of MFA: DDC: DMSO: Pro-Lipo Duo: Hydration media: ultra-purified water (dilution) was 1:1: 4: 20:36: $100 \mathrm{w} / \mathrm{w}$, respectively.

For comparison purposes, MFA free-liposomes and DDC free-liposomes were prepared using the same procedure without MFA and/or DDC.

\section{Preparation of sonicated MFA-DDC based liposomes}

Freshly prepared samples $(n=6)$ of MFA-DDC based liposomes were sonicated in $300 \mathrm{~W}$ and $35^{\circ} \mathrm{C}$ bath sonicator (Digital Pro Heated Ultrasonic Cleaner, Huiyuan Int' Commerce \& Exhibition Co., China) for 60 minutes (Woodbury et al., 2006).

\section{Preparation of lyophilized MFA-DDC based liposomes}

Freshly prepared MFA-DDC based liposomes (n=6), with or without inclusion of sucrose (4 g/g Pro-Lipo Duo) during hydration procedure, were kept overnight in an ultra-low freezer $\left(-80^{\circ} \mathrm{C}\right)$ (Sanyo Electric CO. Lt, Japan) and lyophilized using freeze dryer (LTE Scientific Ltd, Great Britain). The drying powders obtained were then reconstituted to the original volume using ultra-purified water (Kannan et al., 2015).

\section{In-vitro characterization of MFA-DDC based liposomes}

\section{Validation assay}

Detection and quantification of MFA in the prepared liposomal samples were conducted using a new spectrophotometric method. Validation parameters included selectivity, linearity, accuracy and precision, limit of detection (LOD), and limit of quantification (LOQ) as per International Council for Harmonisation (ICH) guideline.

Selectivity: The optical density of drug solution $(25 \mu \mathrm{g} / \mathrm{mL})$ and serial dilutions of blank liposomal samples were measured over UV range (260-400 nm). DMSO was used as a blank while the ultra-purified water was used as a standard for measurements. The wavelength at which the drug showed significant absorption with no significant influence of the liposome components was selected for measurement of MFA absorptions.

Linearity: Linear regression curve analyses were performed by Microsoft Office Exel 2010 software 
(Microsoft, US). The calibration curve was constructed by plotting standard drug concentrations $(80,40,20,10$, and $5 \mu \mathrm{g} / \mathrm{mL}$ ) of serial dilution on $\mathrm{X}$-axis and the obtained drug absorptions on $\mathrm{Y}$-axis.

Accuracy and precision (Intraday and Interday Validations): Intraday validations were performed by measuring the absorbance of six sets of six selected concentrations $(75,65,55,45,35$, and $25 \mu \mathrm{g} / \mathrm{mL})$ of MFA solutions in a single day. On the other hand, interday validations were performed by measuring the absorbance of a single set of six selected concentrations $(75,65,55,45$, 35 , and $25 \mu \mathrm{g} / \mathrm{mL}$ ) using six calibration curves constructed at different days. Percent coefficient of variation (\% CV) and percent error of the average means were calculated to evaluate the precision and accuracy of the method according to the following formulas:

$$
\begin{gathered}
\% \text { error }=(\text { Mean of experimental values }- \text { True value }) / \\
\text { True value }) \times 100 \\
\% \mathrm{CV}=(\text { Standard deviation } / \text { Mean }) \times 100
\end{gathered}
$$

Limit of detection and limit of quantitation: Limit of Detection (LD) and Limit of Quantitation (LQ) were determined by using the following formulas: $\mathrm{LD}=3.3 \mathrm{\sigma} / \mathrm{S}$, $\mathrm{LQ}=10 \sigma / \mathrm{S}$ respectively, where $\sigma=$ the standard deviation of the response (20 replicates of the blank) and $\mathrm{S}=$ the slope of the calibration curve.

\section{Drug entrapment analysis}

The amount of drug entrapped in MFA-DDC based liposomes was determined according to the procedure described by Goh et al. (2014)_ENREF_9and Chiong et al. (2011). All drug amounts were obtained by using the above mentioned spectrophotometric method. The amount of undissolved drug was determined by centrifuging the samples at $12800 \mathrm{G}$ and dissolving the sediment with sufficient amount of DMSO. The dissolved drug was determined by centrifuging the samples at $300,000 \mathrm{G}$ and $20{ }^{\circ} \mathrm{C}$ for 90 minutes and diluting the supernatant with sufficient amount of DMSO. The encapsulation efficacy was calculated according to following formula: $\mathrm{EE}(\%)=$ (Total drug - Free drug)/(Total drug) $\times 100$, where free drug equals the sum of the undissolved drug and the dissolved drug.

\section{Particle size analysis}

The average particle size (ZAve), polydispersity index (PDI), and zeta potential of the prepared liposomal samples were all determined by dynamic light scattering technique using Zetasizer Nano S (Malvern Instruments, Malvern, UK) (Onget al., 2016). Light scattering was monitored at $25^{\circ} \mathrm{C}$, with measurement position of 1.25 $\mathrm{mm}$. In addition to MFA-DDC based liposomes, MFA free-liposomes and MFA-DDC free liposomes were subjected to analysis for comparison. For all formulations, the measurements were conducted three times on the three individual batches of freshly prepared liposomal samples $(n=9)$.

\section{Size reduction analysis}

The effects of sonication and freeze-drying on the drug entrapment and size profiles of MFA-DDC based liposomes were evaluated. Upon comparison with nontreated MFA-DDC based liposomes, the drug entrapment and particles size parameters of sonicated and lyophilized liposomes were determined according to procedures described above. For all formulations, the measurements were conducted three times on the three individual batches of freshly prepared liposomal samples $(n=9)$.

\section{Drug release at different $\mathrm{pH}$ media}

The amount of drug released (free MFA) was determined according to a previously described procedure using the sample and separate method (D'Souza, 2014). An aliquot of freshly prepared samples $(n=3)$ of MFADDC liposomes was added into beakers and mixed continuously with a release media $(\mathrm{pH} 1.2, \mathrm{pH} 5.4$, or $\mathrm{pH}$ 7.4 for 7 hours) at $100 \mathrm{RPM}$ and $37^{\circ} \mathrm{C}$ using a magnetic stirrer. At each hour during experimentation, an aliquot of the mixture was withdrawn and replaced with fresh medium. The aliquot was then centrifuged, and the content of free drug was determined by a spectrophotometer as described above.

\section{Storage study}

The effect of different storage condition on the physical stability of MFA-DDC based liposomes was evaluated with respect to their drug entrapment and size profiles. Three batches of liposomal samples were freshly prepared, and each was separated and stored at ambient room temperature $\left(25 \pm 3^{\circ} \mathrm{C}\right)$ and refrigerated temperature $\left(2-8{ }^{\circ} \mathrm{C}\right)$. Samples for analyses were collected immediately and at two and four weeks after preparation (Chiong et al., 2011; Goh et al., 2014). 


\section{Reproducibility}

The coefficient variation percentage $(\% \mathrm{CV})$ of six different batches of the liposomal samples was calculated to assess the reproducibility of MFA-DDC liposomes with respect to their drug entrapment and particle size parameters (Chiong et al., 2011; Goh et al., 2014).

\section{Experimental animals}

Forty-eight female Sprague-Dawley rats with body weight of 180-220 g were used in the present study. All rats were housed at $12 \mathrm{~h}$ light of the day and $\left(24 \pm 1^{\circ} \mathrm{C}\right)$ room temperature at the Faculty of Medicine and Health Sciences, Universiti Putra Malaysia (UPM). All animals were housed in clean wire-bottomed plastic cages with well-ventilated laboratory conditions and had free access to standard food pellets and drinking tap water. All experiments were carried out according to the protocol approved by the ethical committee of UPM and in accordance with the UPM Institutional Animal Care and Use Committee.

\section{Maximum tolerated doses selection}

Eight groups (6 rats each) received a single dose of either oral or intraperitoneal liposomal MFA (0, 20, 40, and $80 \mathrm{mg} / \mathrm{kg}$ ) at equivalent doses. All treated rats were observed during the post dosage periods for any signs of toxicity. The dose at which rats showed normal activity and behavior was selected as the MTDs in the present study.

\section{Biochemical analysis}

At six hours after liposomal MFA exposure, blood samples were collected and centrifuged at 3000 $\mathrm{G}$ for 15 minutes for serum separation. Serum samples were immediately assayed to determine aspartate aminotransferase (AST), creatine kinase (CK), lactate dehydrogenase (LDH), and serum electrolytes such as sodium, potassium, and chloride.

\section{Carrageenan induced acute paw edema test}

Six groups of rats ( 6 each) received a single oral dose $(0,20,40$, and $80 \mathrm{mg} / \mathrm{kg})$ and intraperitoneal dose $(0$ and $20 \mathrm{mg} / \mathrm{kg}$ ) of MFA-DDC based liposomes. The rats were then subjected to carrageenan induced with acute paw edema test according to the experimental protocol of Neha Mohan et al. (2013). The overnight fasting rats received the treatments 30 minutes before they were induced with paw inflammation by injecting $100 \mu \mathrm{L}$ of carrageenan $(1 \%$, $\mathrm{W} / \mathrm{V}$ ) into the left paw of each rat. The hind paw volume of each rat was then measured using a plethysmometer (Basile Ugo, Italy) at 0, 1, 2, 3, 4, 5, and 6 hours after carrageenan injection. The percentage of edema inhibition was calculated according to the following formula:

Edema inhibition $(\%)=\frac{(\mathrm{Vt}-\mathrm{V} 0) \text { control }-(\mathrm{Vt}-\mathrm{V} 0) \text { treatment }}{(\mathrm{Vt}-\mathrm{V} 0) \text { control }} \times 100$

where $\mathrm{V}_{0}$ is initial paw volume, and $\mathrm{V}_{\mathrm{t}}$ is the paw volume at a specific time point.

\section{Statistical analysis}

All results were presented as mean \pm SEM. The comparative analysis was conducted using Student's t-test for comparisons between two groups and one-way analysis of variance (ANOVA) for multiple comparisons (IBM SPSS Statistics 20). The $P$-value $<0.05$ was considered statistically significant.

\section{RESULTS AND DISCUSSION}

\section{Spectrophotometric method validation}

Drug analysis must be conducted using valid methods to show a degree of selectivity, sensitivity accuracy, and precision that matches the analytical requirements (Kunasekaran, Krishnamoorthy, 2014; Siddiqui, Alothman, Rahman, 2013; Wagner, Vorauer-Uhl, 2010). In the present study, a simple, rapid, effective, and cost-saving method was developed for MFA detection and quantification in liposomal preparations.

Spectrum scanning analysis showed that MFA has UV absorption at the wavelength range of 240-360 $\mathrm{nm}$ (Figure 1). However, the comparative findings of ultra-pure water standard spectra with those of MFA freeliposomal samples showed satisfied selectivity at 360 $\mathrm{nm}$ where liposome components showed no significant interference with MFA absorption. Data obtained from MFA standard calibration curve showed a high correlation between test drug concentrations and corresponding absorbance values with a correlation coefficient of 0.999 and linearity range of $5-80 \mu \mathrm{g} / \mathrm{mL}$ (Figure 2). In addition, all intraday and interday method validations as per ICH guideline showed acceptable precision and accuracy values with the coefficient of variation and percentage error less than 5\% with different drug concentrations. In addition, the limit of detection (LOD) and limit of quantification (LOQ) were found to be 1.19 and $3.62 \mu \mathrm{g} /$ 
$\mathrm{mL}$, respectively. Together, these findings suggest that the described spectrophotometric method is valid for MFA analysis in the liposomal preparations. In addition, this method is rapid and cost-effective which may be suitable for analysis of a large number of samples. Unlike previously described spectrophotometric methods, the use of DMSO (as drug solvent) in the present method is effective to dissolve a high amount of MFA which increases the suitability for a detection of a wide range of drug concentrations (Dinç, Yücesoy, Onur, 2002; Othman, Awadis, 2009). Furthermore, the method introduced by the present study does not require additional analytical reagents in contrast to some previously described methods (Alarfaj, Altamimi, Almarshady, 2009).

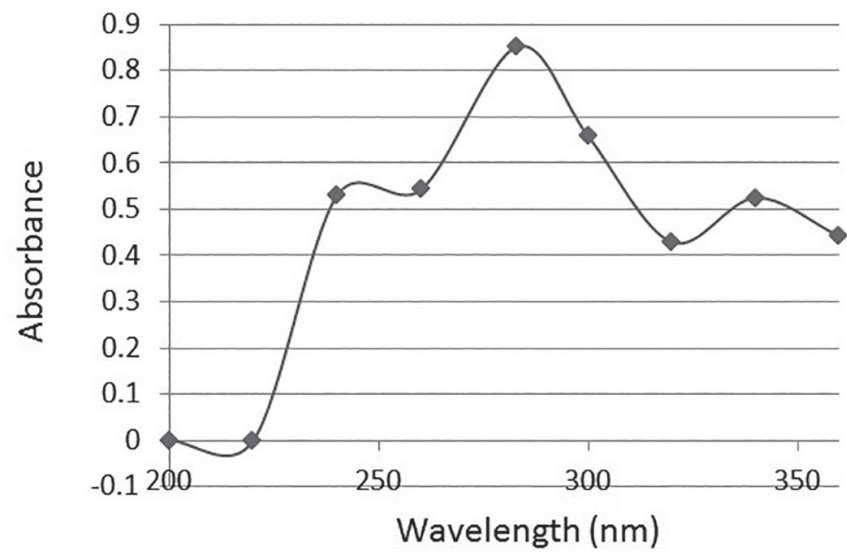

FIGURE 1 - UV spectrum of MFA $(25 \mu \mathrm{g} / \mathrm{mL})$ dissolved in DMSO at a wavelength range of 200-360 nm.

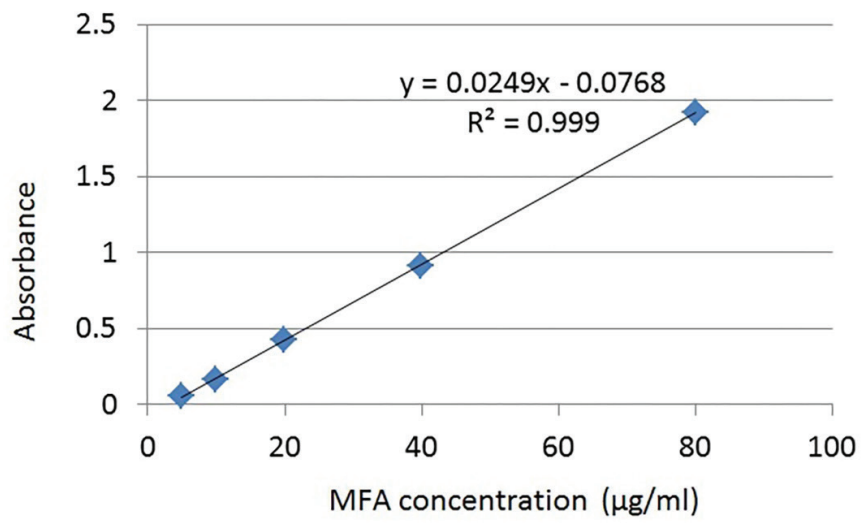

FIGURE 2 - Mefenamic acid calibration curve constructed via standard solution with five concentrations in the range from $5-80 \mu \mathrm{g} / \mathrm{mL}$.

\section{In vitro characterization of MFA-DDC based liposomes}

Drug entrapment and particle size profiles

Figures (3-6) show the influence of liposomes chemical components (with or without DDC) and prolongation of hydration time on drug entrapment and size parameters. As demonstrated in Figure 3, the encapsulation efficacy of MFA-DDC based liposomes was approximately nine-fold greater than that of MFA-DDC free liposomes when different hydration times were employed. The results indicate that MFA-DDC liposomes are able to entrap $47.04 \mathrm{mg}$ of MFA/g Pro-Lipo Duo, whereas MFA-DDC free liposomes were not able to entrap more than $7.7 \mathrm{mg}$ of MFA/g Pro-Lipo Duo. No significant change in drug entrapment efficacy of all prepared liposomes was observed by the Tukey's test when prolongation of hydration time (up to 10 hours) was employed.

Also, the results showed that MFA-DDC based liposomes demonstrated significantly $(\mathrm{p}<0.05)$ smaller particles size than those of MFA-DDC free liposomes when different hydration times were employed (Figure $4)$. No significant change in the size profiles of all prepared liposomes was observed by the Tukey's test when prolongation of hydration time (up to 10 hours) was employed. Together, these findings may indicate that the physical properties of MFA-loaded liposomes prepared in the present study are largely dependent on the chemical additives to these liposomes rather than the prolongation of hydration time. The improvement in the encapsulation efficacy and particles size reduction by DDC involvement may suggest structural alterations on the phospholipids of Pro Lipo Duo. Studies indicated the ability of DDC to form bridging ligands and pose strong binding properties with various therapeutic agents (Han et al., 2013; Lai, Wang, 2002; Wehbe et al., 2016).

The polydispersity index (PDI) of all liposomes in the present study including MFA-DDC based liposomes ranged from 0.2-0.35 (Figure 5). The PDI is a measurement that reflects the uniformity of particle sizes of colloidal dispersions; the homogenous vesicles give values ranging from 0-0.5 while those of the heterogeneous ones give values ranging from 0.5-1.0 (Wen, Farid, Kassem, 2014; Zhang, Fan, Smith, 2009). The findings of the current work indicate narrow particle size distribution of all prepared liposomes.

Zeta potential is a value that reflects the strength of electrostatic repulsion between similarly charged particles and indicates colloids stability (MuÈller, MaÈder, Gohla, 2000; Wen, Farid, Kassem, 2014). Vesicles that give ZP values more than $\pm 30 \mathrm{Mv}$ pose strong repulsive forces and have less potential to develop aggregation or flocculation (Frestaet al.,1993; Wen, Farid, Kassem, 2014). As shown in Figure 6, ZP of all liposomal formulations including MFA-DDC based liposomes ranged from -45.80 to -77.90 . These results suggest that all liposomal preparations used in the present work have colloidal stability resulted from 
strong electrostatic repulsion between liposomes (Dinç, Yücesoy, Onur, 2002; Samad, Sultana, Aqil, 2007).

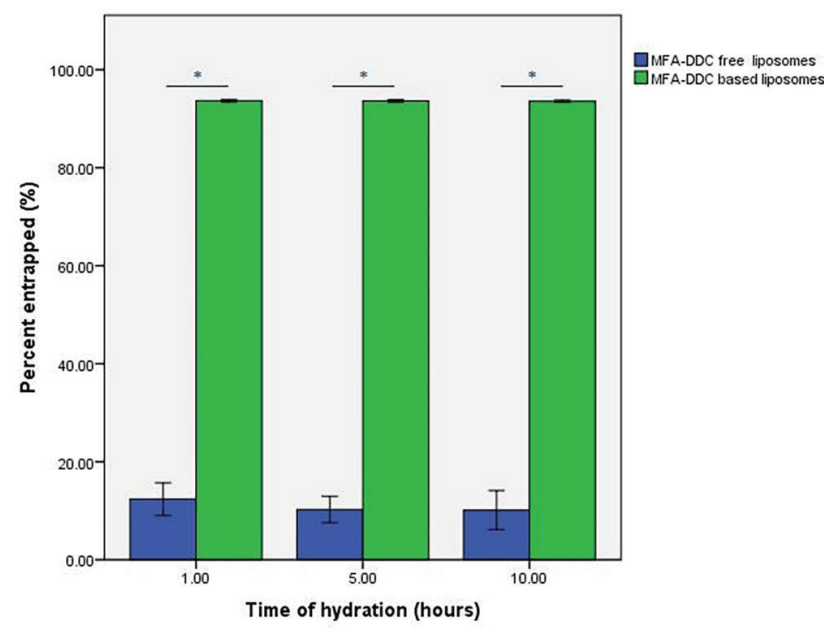

FIGURE 3 - Entrapment efficiency (\%) when different liposomal components and duration of hydration were employed. $(*)$ Indicates statistically significant difference between the formulations by the Student's t-test.

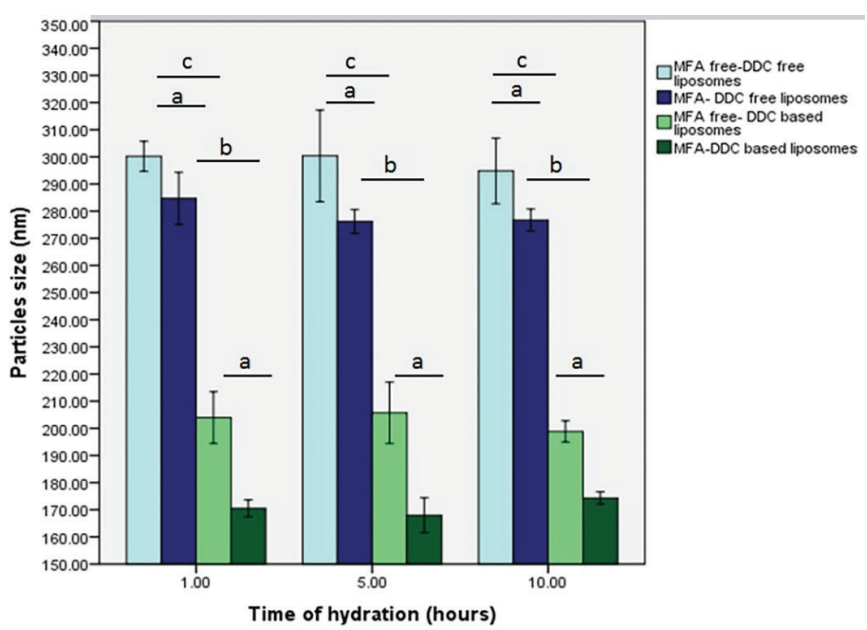

FIGURE 4 - Particle size (nm) when different liposomal components and hydration times were employed. (a) Indicates significant difference between MFA-loaded liposomes and their corresponding MFA free-liposomes by the Student's t-test. (b) Indicates significant difference between MFA-DDC free liposomes and MFA-DDC based liposomes by the Student's t-test. (c) Indicates significant difference between MFA freeDDC free liposomes and MFA free-DDC based liposomes by the Student's t-test.

\section{Effect of sonication and lyophilization on drug entrapment and size profiles of liposomes}

Small liposomes pose several advantages over big liposomes with respect to their longer circulating half-lives and better tissue penetration. Previous studies

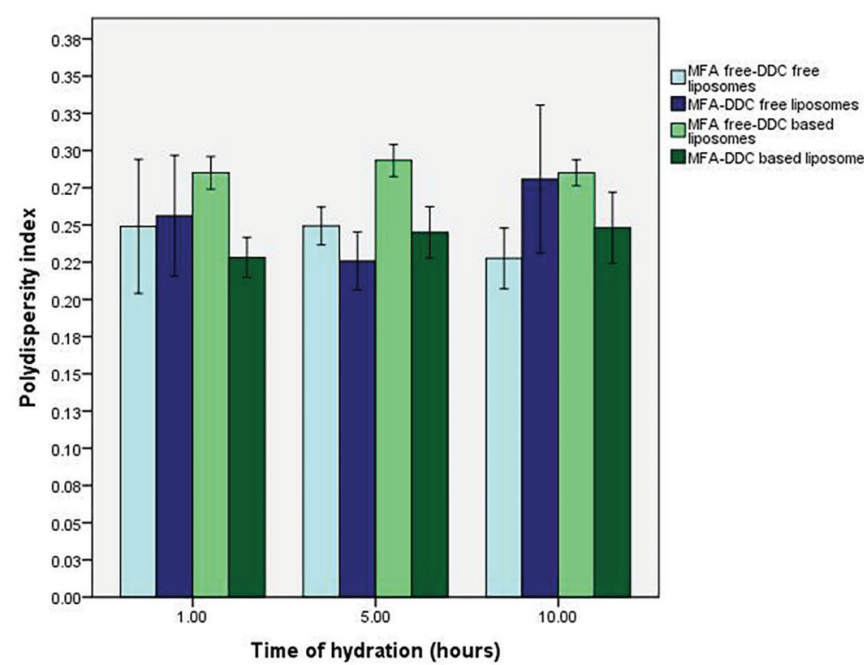

FIGURE 5 - Polydispersity index of the particles size when different liposomal components and hydration times were employed.

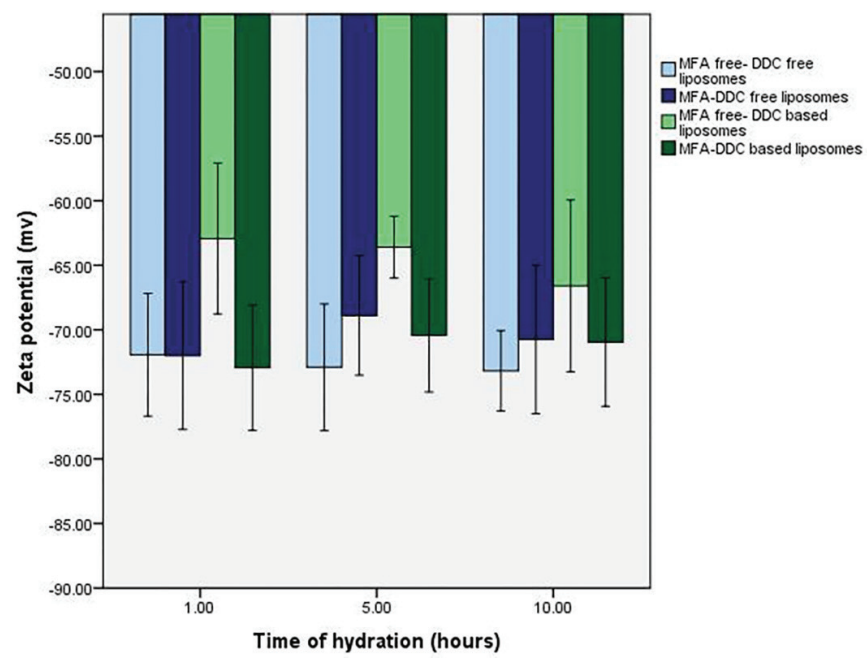

FIGURE 6 - Zeta potential (mv) when different liposomal components and duration of hydration employed.

indicated that particle size of liposomes could impact the interaction of the entrapped drug with cells, its circulation half-life, and bioavailability (Chen, Langer, 1998; Chen et al., 2011; Elorza et al., 1993).

Several methods are employed to reduce particle size of liposomes including sonication and freezedrying methods (Lee, Lee \& Choi, 2007). In the present study, MFA-DDC based liposomes were subjected to lyophilization (with or without sucrose) and sonication to discover their effect on the liposomes size and their drug entrapment profile.

As presented in Table I, sonication slightly increased the average particle size (from 173.16 to $184.29 \mathrm{~nm}$ ). On the other hand, lyophilization with sucrose reduced the particle size from $173.16 \mathrm{~nm}$ to $144.12 \mathrm{~nm}$, while lyophilization without sucrose increased the particle size 
TABLE I - Drug entrapment and particle size profile before and after size reduction treatments

\begin{tabular}{lccccc}
\hline \multirow{2}{*}{ Formulation ID } & \multicolumn{2}{c}{ Entrapment profile } & \multicolumn{3}{c}{ Size profile } \\
\cline { 2 - 6 } & $\begin{array}{c}\text { Amount entrapped } \\
\text { (mg/g Pro-Lipo) }\end{array}$ & $\begin{array}{c}\text { Percent } \\
\text { entrapped }\end{array}$ & $\begin{array}{c}\text { Particle size } \\
\text { (nm) }\end{array}$ & $\begin{array}{c}\text { Poly-dispersity } \\
\text { index }\end{array}$ & Zeta potential \\
\hline $\begin{array}{l}\text { MFA-DDC based liposomes } \\
\text { (without treatment) }\end{array}$ & $46.72 \pm 0.18$ & $93.45 \pm 0.36$ & $173.16 \pm 1.63$ & $0.23 \pm 0.003$ & $-64.81 \pm 1.12$ \\
$\begin{array}{l}\text { Sonicated MFA-DDC based } \\
\text { liposomes }\end{array}$ & $43.74 \pm 0.43^{*}$ & $87.47 \pm 0.87^{*}$ & $184.29 \pm 1.87$ & $0.32 \pm 0.01$ & $-61.10 \pm 2.51$ \\
$\begin{array}{l}\text { Lyophilized MFA-DDC based } \\
\text { liposomes (without sucrose) }\end{array}$ & $45.06 \pm 0.21^{*}$ & $90.11 \pm 0.43^{*}$ & $377.16 \pm 8.12$ & $0.45 \pm 0.02$ & $-73.01 \pm 0.21$ \\
$\begin{array}{l}\text { Lyophilized MFA-DDC based } \\
\text { liposomes (with sucrose) }\end{array}$ & $45.73 \pm 0.07^{*}$ & $91.47 \pm 0.15^{*}$ & $144.12 \pm 0.75$ & $0.24 \pm 0.009$ & $-58.43 \pm 0.07$ \\
\hline
\end{tabular}

(*) Indicates statistically significant difference from MFA-DDC based liposomes (without treatment) by the Dunnett's test

up to $377.16 \mathrm{~nm}$. Moreover, the PDI value was not affected by sucrose-lyophilization, but it increased in lyophilization without sucrose and sonication. All these suggests that only lyophilization with sucrose was effective to reduce the particles size in narrow size distribution, indicating that sucrose provides a cryoprotective effect that partially prevents liposomes fusion during the lyophilization process. Nevertheless, both sonication and lyophilization (with or without sucrose) caused significant $(\mathrm{P}<0.05)$ reduction in drug entrapment efficacy and capacity, suggesting that these techniques will not be suitable to produce small MFA-DDC liposomes.

\section{Effect of $\mathrm{pH}$ on drug release properties}

The $\mathrm{pH}$ differences between various tissue and cellular environments of the human body can be a limiting factor on drug release profile from the liposomes (Chu, Szoka, 1994). For example, $\mathrm{pH}$-sensitive liposomes provide a controlled drug release in cancer and inflamed tissues where the intracellular $\mathrm{pH}$ ranges from 4-6 (Mo, Gu, 2016; Steen, Steen, Reeh, 1995). In the current study, MFA release from the liposomes was evaluated in various $\mathrm{pH}(1.2,5.4$, and 7.4$)$ media over 7 hours. MFA-DDC based liposomes provided a $\mathrm{pH}$-dependent gradient drug release as drug release significantly $(\mathrm{p}<0.05)$ increased by decreasing the $\mathrm{pH}$ of the media (Figure 7). The robust release of MFA in the strongly acidic medium (pH 1.2) may suggest that these liposomes are relatively not stable in the gastric fluid and not effective by the oral route of administration (Thamphiwatana et al., 2013). On the other hand, these liposomes caused small burst and sustained drug release in $\mathrm{pH} 5.4$ medium that may suggest the suitability of these liposomes in targeting inflamed tissues that have weak acidic environments (Steen, Steen, Reeh,
1995). In addition, the drug release at $\mathrm{pH} 7.4$ was almost "off" (less than 12\%) which may indicate the stability of these liposomes in the blood that can avoid fast drug release, reduce the systemic side effects, and prevent drug uptake by the untargeted tissues (Sercombe et al., 2015). All these results may indicate that the developed liposomes may enhance MFA targeting to the inflamed tissues, considering the use of other routes of administration rather than the oral dosage in order to achieve the maximum therapeutic benefits by liposomes encapsulation of MFA.

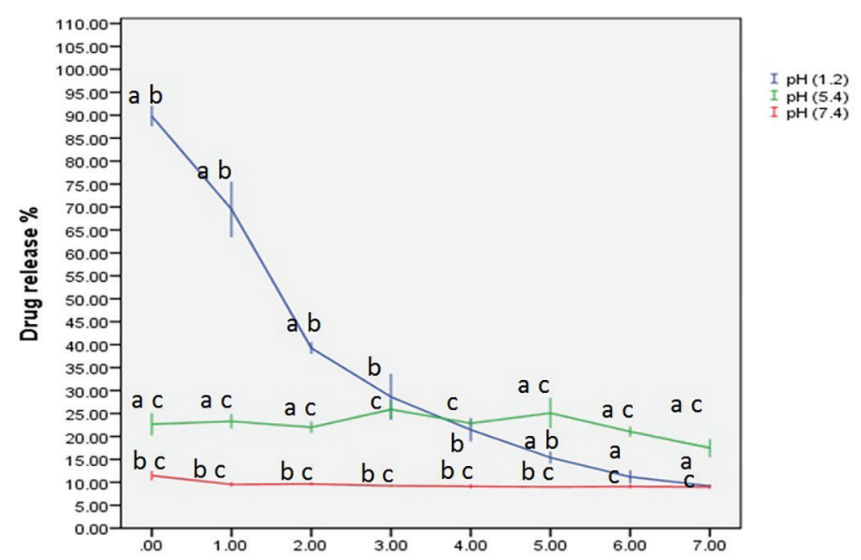

FIGURE 7 - Cumulative drug release at different $\mathrm{pH}$ media. (a) Indicates significant difference between the amount of drug release at $\mathrm{pH}(1.2)$ and $\mathrm{pH}$ (5.4) by the Student's t-test. (b) Indicates significant difference between the amount of drug release at $\mathrm{pH}(1.2)$ and $\mathrm{pH}(7.4)$ by the Student's t-test. (c) Indicates significant difference between the amount of drug release at $\mathrm{pH}$ (5.4) and $\mathrm{pH}$ (7.4) by the Student's t-test.

\section{Effect of storage conditions on drug entrapment and particle size of MFA-DDC liposomes}

Storage study is important to determine the physical 
stability of liposomes stored at different storage conditions. Improper storage ambient temperature may increase phospholipid membrane fluidity that may finally result in rapid hydrolysis of the liposomes (Samad, Sultana, Aqil, 2007). As seen in Table II, MFA-DDC based liposomes stored at both room and refrigerated temperatures exhibited good stability with no significant difference in drug entrapment and particle size profile during the four weeks of storage. These findings indicate that the prepared liposomes can withstand the duration of storage whereby the quality of these preparations remains satisfactory or unaffected.

\section{Reproducibility of MFA-DDC based liposomes}

Reproducibility test is important to assess the precision and repeatability of the results between different batches (Chiong et al., 2011; Goh et al., 2014). As shown in Table III, the percent coefficient of variation (CV \%) of all test parameters was not found to be more than $7.2 \%$. This finding indicates that MFA-DDC based liposomes are reproducible via the same formulation and methodology.

\section{Selection of the maximum tolerated doses of MFA-DDC based liposomes}

All control rats and all members that received oral doses of MFA-DDC based liposomes together with those received intraperitoneal doses of $20 \mathrm{mg} / \mathrm{kg}$ liposomal MFA exhibited no signs of toxicity with normal activities and behaviors. On the other hand, rats that received intraperitoneal doses (40 and $80 \mathrm{mg} / \mathrm{kg}$ ) of the liposomal drug exhibited acute extrapyramidal symptoms (EPS) mainly dystonia, akinesia, limb tremor, and dyskinesia. These toxicity signs were observed at distinct consecutive stages in a dose-dependent manner with different onset and duration of the reaction as elucidated in Table IV. Based on these findings, the MTD of the orally administrated of MFA-DDC based liposomes was selected at $80 \mathrm{mg} /$ $\mathrm{kg}$ while for those administrated intraperitoneally was selected at $20 \mathrm{mg} / \mathrm{kg}$.

The extrapyramidal system is modulated by dopamine and regulates skeletal muscle tone (Divac et al., 2014). Thus, the induced EPS of MFA-DDC liposomes may indicate an interference with the dopaminergic system. One of the major characteristics of EPS induced by MFA-DDC liposomes is an acute dystonic reaction. Dystonia is a neurological condition characterized by sustained or repetitive muscle contractions that produce twisting movements and abnormal postures (Albanese, 2007). Dystonia may be genetically inherited or resulted from a broad range of causes including genetic mutations, birth injury, stroke, brain tumors, certain infections, and drugs treatment. Inducing dystonia in rodents would be a promising tool for understanding the mechanisms

TABLE II - Drug entrapment and size entrapment of MFA- DDC liposomes kept in different storage conditions

\begin{tabular}{ccccccc}
\hline $\begin{array}{c}\text { Storage } \\
\text { temperature } \\
\left({ }^{\circ} \mathbf{C}\right)\end{array}$ & \multicolumn{2}{c}{ At starting time } & \multicolumn{2}{c}{ After 2 weeks } & \multicolumn{2}{c}{ After 4 weeks } \\
\cline { 2 - 7 } & $\begin{array}{c}\text { Amount } \\
\text { entrapped }\end{array}$ & $\begin{array}{c}\text { Percent } \\
\text { entrapped }\end{array}$ & $\begin{array}{c}\text { Amount } \\
\text { entrapped }\end{array}$ & $\begin{array}{c}\text { Percent } \\
\text { entrapped }\end{array}$ & $\begin{array}{c}\text { Amount } \\
\text { entrapped }\end{array}$ & $\begin{array}{c}\text { Percent } \\
\text { entrapped }\end{array}$ \\
\hline 23 & $46.82 \pm 0.06$ & $93.63 \pm 0.11$ & $46.97 \pm 0.12$ & $93.94 \pm 0.24$ & $46.90 \pm 0.09$ & $93.80 \pm 0.18$ \\
4 & $46.95 \pm 0.09$ & $93.88 \pm 0.18$ & $47.14 \pm 0.11$ & $94.27 \pm 0.23$ & $47.04 \pm 0.12$ & $94.08 \pm 0.25$ \\
\hline
\end{tabular}

TABLE III - Reproducibility of MFA-DDC based liposomes

\begin{tabular}{lccccc}
\hline & \multicolumn{2}{c}{ Entrapment profile } & \multicolumn{3}{c}{ Size profile } \\
\cline { 2 - 6 } & $\begin{array}{c}\text { Amount entrapped } \\
\text { (mg/g Pro-Lipo) }\end{array}$ & $\begin{array}{c}\text { Percent } \\
\text { entrapped }\end{array}$ & $\begin{array}{c}\text { Particle size } \\
(\mathbf{n m})\end{array}$ & $\begin{array}{c}\text { Polydispersity } \\
\text { index }\end{array}$ & $\begin{array}{c}\text { Zeta } \\
\text { potential (mv) }\end{array}$ \\
\hline Batch \#1 & 46.15 & 92.30 & 186.17 & 0.25 & -66.60 \\
Batch \#2 & 46.69 & 93.37 & 175.67 & 0.26 & -70.33 \\
Batch \#3 & 47.10 & 94.20 & 180.73 & 0.27 & -75.13 \\
Batch \#4 & 46.99 & 93.99 & 181.13 & 0.26 & -64.83 \\
Batch \#5 & 47.11 & 94.22 & 169.13 & 0.22 & -66.07 \\
Batch \#6 & 46.53 & 93.07 & 152.17 & 0.24 & -71.87 \\
\hline Mean \pm S.E.M & $46.76 \pm 0.15$ & $93.53 \pm 0.31$ & $174.17 \pm 4.99$ & $0.25 \pm 0.007$ & $-69.14 \pm 10.62$ \\
CV \% & 0.8 & 0.8 & 7 & 7.2 & 5.8 \\
\hline
\end{tabular}


TABLE IV - The extrapyramidal symptoms induced by intraperitoneal administrated MFA-DDC liposomes

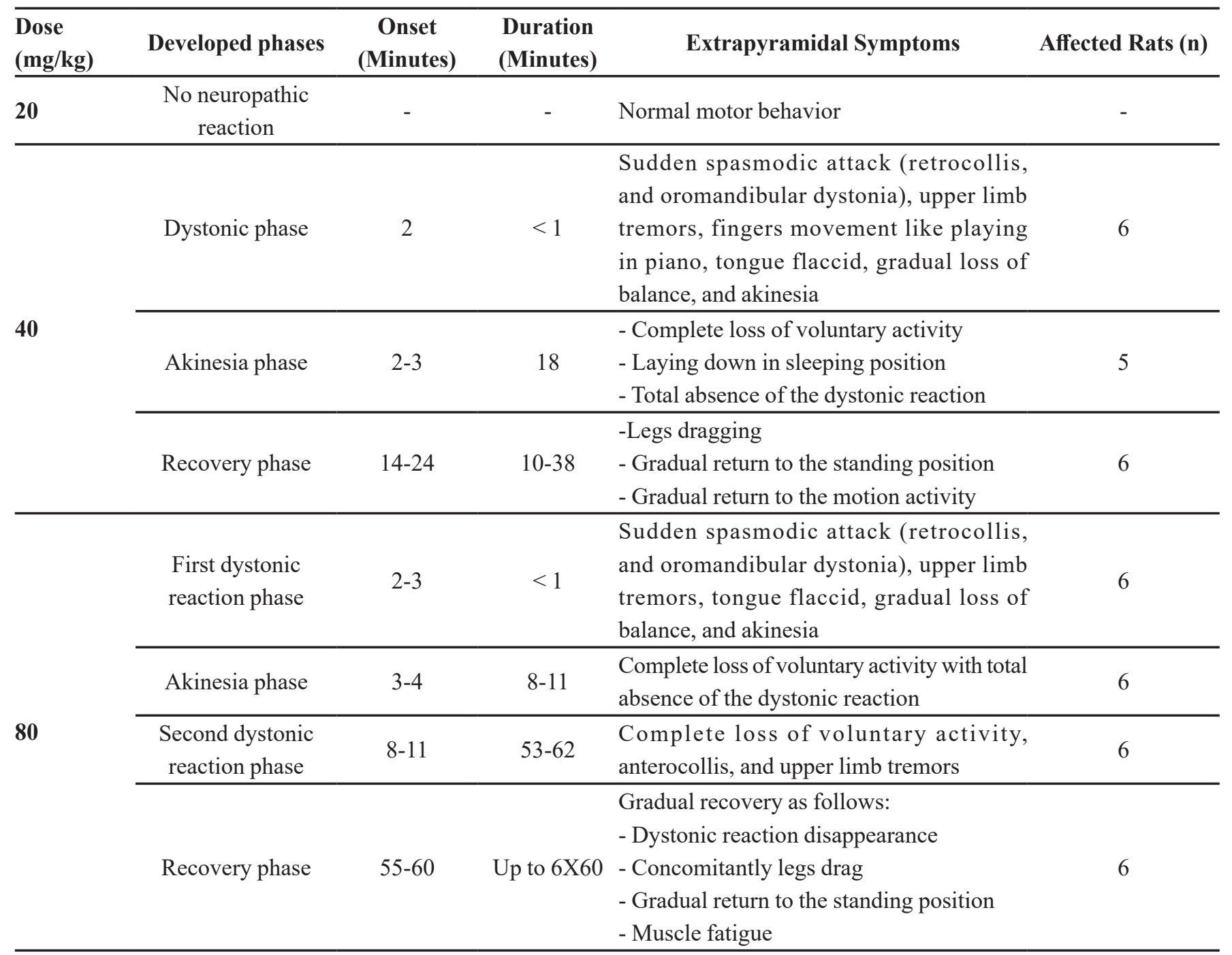

underlying dystonia and identifying novel therapeutics in the clinical treatments (Raike, Jinnah, Hess, 2005). The present study introduces a new model for inducing acute dystonia in rats by MFA-DDC based liposomes. This model exhibits a rapid onset of dystonic reaction and poses distinct consecutive phases which can be easily recognized and scored during the experimentation.

All rats exposed to the oral administration of MFADDC based liposomes demonstrated no EPS at all doses level. This may indicate that the intraperitoneal dosage of MFA-DDC based liposomes resulted in higher drug bioavailability than the one resulted by the oral route of administration. In comparison to the environment of the peritoneal fluids, the gastric juice has stronger acidic $\mathrm{pH}$ which may result in rapid drug release from the liposomes that reduces the amount of drug reaching the blood circulation.

\section{Biochemical alterations induced by MFA-DDC liposomes}

All members of the orally administrated MFADDC liposomes demonstrated no biochemical alterations of the tested parameters. Moreover, rats subjected to intraperitoneal MFA-DCC liposomes showed a significant elevation in a dose-dependent manner (particularly 40 and $80 \mathrm{mg} / \mathrm{kg}$ ) in AST, CK, and LDH (Table V). These enzymes are released into the bloodstream in case of muscle injury or prolonged muscle contraction (Brancaccio, Lippi, Maffulli, 2010; Chavez et al., 2016; Elsayed, Reilly, 2010). This may suggest that the severity of dystonia by MFA-DDC based liposomes can be indirectly quantified by measuring serum levels of AST, CK, $\mathrm{LDH}$, and $\mathrm{K}^{+}$in future studies. 
TABLE V - Biochemical alterations demonstrated by rats exposed to oral or intraperitoneal MFA-DDC liposomes

\begin{tabular}{|c|c|c|c|c|c|c|c|}
\hline \multirow[b]{2}{*}{ Treatment group } & \multirow{2}{*}{$\begin{array}{l}\text { Mefenamic acid } \\
\text { dosage }(\mathrm{mg} / \mathrm{kg})\end{array}$} & \multicolumn{3}{|c|}{ Serum muscle enzymes } & \multicolumn{3}{|c|}{ Serum electrolytes } \\
\hline & & $\begin{array}{l}\text { AST } \\
(\mathbf{U} / \mathbf{L})\end{array}$ & $\begin{array}{c}\text { CK } \\
(\mathbf{U} / \mathbf{L})\end{array}$ & $\begin{array}{l}\text { LDH } \\
(\mathrm{U} / \mathrm{L})\end{array}$ & $\begin{array}{c}\mathrm{Na} \\
(\mathrm{mmol} / \mathrm{L})\end{array}$ & $\begin{array}{c}\mathrm{K} \\
(\mathrm{mmol} / \mathrm{L})\end{array}$ & $\begin{array}{c}\mathrm{Cl} \\
(\mathrm{mmol} / \mathrm{L})\end{array}$ \\
\hline \multirow{2}{*}{$\begin{array}{l}\text { Orally administrated } \\
\text { MFA-DDC based } \\
\text { liposomes }\end{array}$} & 20 & $116.33 \pm 6.67$ & $281.00 \pm 26.45$ & $199.50 \pm 25.16$ & $143.00 \pm 5.11$ & $4.60 \pm 0.30$ & $108.50 \pm 1.86$ \\
\hline & 40 & $109.50 \pm 6.83$ & $262.83 \pm 19.39$ & $232.33 \pm 14.65$ & $143.67 \pm 3.01$ & $4.48 \pm 0.09$ & $107.17 \pm 3.05$ \\
\hline \multirow{3}{*}{$\begin{array}{l}\text { Intraperitoneally } \\
\text { administrated } \\
\text { MFA-DDC based } \\
\text { liposomes }\end{array}$} & 20 & $121.00 \pm 5.65$ & $301.33 \pm 34.20$ & $260.33 \pm 21.19$ & $144.17 \pm 2.56$ & $4.60 \pm 0.30$ & $105.83 \pm 1.22$ \\
\hline & 40 & $148.33 \pm 6.70$ & $361.17 \pm 64.02$ & $327.00 \pm 35.18$ & $148.17 \pm 1.97$ & $4.48 \pm 0.09$ & $108.83 \pm 1.35$ \\
\hline & 80 & $188.33 \pm 9.90^{*}$ & $853.17 \pm 134.67^{*}$ & $841.83 \pm 178.84^{*}$ & $147.50 \pm 2.55$ & $4.70 \pm 0.29 *$ & $107.17 \pm 2.04$ \\
\hline
\end{tabular}

(*) Indicates statistically significant difference $(\mathrm{P}<0.05)$ from control by the Dunnett's test

\section{Anti-inflammatory efficacy}

Carrageenan is sulfated polysaccharides extracted from red seaweeds. This compound is widely used in the pharmacological studies to induce short-lasting paw edema in animal models to assess the antiinflammatory properties of various chemicals including NSAIDs (Fehrenbacher, Vasko, Duarte, 2012). As seen in Table VI, all rats subjected to MFA-DDC based liposomes exhibited significantly $(\mathrm{p}<0.05)$ higher antiinflammatory effect in comparison to the control group at various time intervals following administration. Orally-treated rats demonstrated dose-dependent reduction of paw edema volume with rapid onset of action observed among members that received higher doses of MFA. Moreover, the intraperitoneally-treated rats with MFA-loaded liposomes showed significantly $(p<0.05)$ less edema volume than those treated orally. The intraperitoneally-treated rats exhibited an inhibition percentage of $94.27 \%$ of the inflammation at 6 hours following carrageenan injection, while those receiving liposomes orally demonstrated a maximum of $78 \%$. These findings may suggest that the intraperitoneal administration of MFA-loaded liposomes exhibits better anti-inflammatory effect at lower drug dosage than the one seen by the orally administrated MFA-loaded liposome.

TABLE VI - Mean edema volume and percentage of inhibition at different time intervals in carrageenan-induced paw edema test

\begin{tabular}{|c|c|c|c|c|c|c|c|c|c|c|c|c|c|}
\hline \multirow{2}{*}{$\begin{array}{l}\text { Treatment } \\
\text { group }\end{array}$} & \multirow{2}{*}{$\begin{array}{c}\text { Mefenamic } \\
\text { acid dosage } \\
(\mathrm{mg} / \mathrm{kg})\end{array}$} & \multicolumn{6}{|c|}{ Edema volume (mL) } & \multicolumn{6}{|c|}{ Inhibition (\%) } \\
\hline & & $1 \mathrm{~h}$ & $2 \mathrm{~h}$ & $3 \mathbf{h}$ & $4 \mathrm{~h}$ & 5 h & $6 \mathrm{~h}$ & $1 \mathrm{~h}$ & $2 \mathrm{~h}$ & $3 \mathbf{h}$ & $4 \mathrm{~h}$ & $5 \mathrm{~h}$ & $6 \mathrm{~h}$ \\
\hline $\begin{array}{l}\text { Negative control } \\
\text { (Vehicle only) }\end{array}$ & 0 & $\begin{array}{c}0.22 \pm \\
0.47\end{array}$ & $\begin{array}{c}0.47 \pm \\
0.04\end{array}$ & $\begin{array}{c}0.75 \pm \\
0.03\end{array}$ & $\begin{array}{c}1.05 \pm \\
0.06\end{array}$ & $1.4 \pm 0.04$ & $\begin{array}{c}1.57 \pm \\
0.09\end{array}$ & $\mathrm{~N} / \mathrm{A}$ & $\mathrm{N} / \mathrm{A}$ & N/A & $\mathrm{N} / \mathrm{A}$ & N/A & N/A \\
\hline \multirow{4}{*}{$\begin{array}{l}\text { MFA-DDC } \\
\text { based liposomes } \\
(\mathrm{PO})\end{array}$} & 0 & $\begin{array}{l}0.26 \pm \\
0.059\end{array}$ & $\begin{array}{c}0.49 \pm \\
0.07\end{array}$ & $\begin{array}{c}0.70 \pm \\
0.05\end{array}$ & $\begin{array}{c}0.89 \pm \\
0.04\end{array}$ & $\begin{array}{l}1.13 \pm \\
0.06 *\end{array}$ & $\begin{array}{l}1.21 \pm \\
0.15^{*}\end{array}$ & -18.18 & -4.26 & 6.67 & 15.24 & 19.29 & 22.93 \\
\hline & 20 & $\begin{array}{l}0.22 \pm \\
0.029\end{array}$ & $\begin{array}{c}0.45 \pm \\
0.07\end{array}$ & $\begin{array}{c}0.68 \pm \\
0.04\end{array}$ & $\begin{array}{l}0.78 \pm \\
0.02 *\end{array}$ & $\begin{array}{l}1.1 \pm \\
0.05^{*}\end{array}$ & $\begin{array}{l}1.31 \pm \\
0.20^{*}\end{array}$ & 0.00 & 4.26 & 9.33 & 25.71 & 21.43 & 16.56 \\
\hline & 40 & $\begin{array}{l}0.23 \pm \\
0.042\end{array}$ & $\begin{array}{c}0.31 \pm \\
0.03\end{array}$ & $\begin{array}{l}0.38 \pm \\
0.03 *\end{array}$ & $\begin{array}{l}0.55 \pm \\
0.05^{*}\end{array}$ & $\begin{array}{c}0.84 \pm \\
0.11^{*}\end{array}$ & $\begin{array}{l}0.81 \pm \\
0.22 *\end{array}$ & -4.55 & 34.04 & 49.33 & 47.62 & 40.00 & 48.41 \\
\hline & 80 & $\begin{array}{c}0.06 \pm \\
0.02\end{array}$ & $\begin{array}{l}0.12 \pm \\
0.01 *\end{array}$ & $\begin{array}{l}0.15 \pm \\
0.02 *\end{array}$ & $\begin{array}{l}0.33 \pm \\
0.03 *\end{array}$ & $\begin{array}{l}0.36 \pm \\
0.04 *\end{array}$ & $\begin{array}{l}0.35 \pm \\
0.09 *\end{array}$ & 72.73 & 74.47 & 80.00 & 68.57 & 74.29 & 77.71 \\
\hline \multirow{2}{*}{$\begin{array}{l}\text { MFA-DDC } \\
\text { based liposomes } \\
\text { (IP) }\end{array}$} & 0 & $\begin{array}{c}0.22 \pm \\
0.16\end{array}$ & $\begin{array}{c}0.41 \pm \\
0.03\end{array}$ & $\begin{array}{c}0.67 \pm \\
0.04\end{array}$ & $\begin{array}{l}0.86 \pm \\
0.03^{*}\end{array}$ & $\begin{array}{l}1.08 \pm \\
0.04^{*}\end{array}$ & $\begin{array}{l}1.17 \pm \\
0.05^{*}\end{array}$ & 0.00 & 12.77 & 10.67 & 18.10 & 22.86 & 25.48 \\
\hline & 20 & $\begin{array}{c}0.07 \pm \\
0.02\end{array}$ & $\begin{array}{c}0.05 \pm \\
0.03 *\end{array}$ & $\begin{array}{c}0.05 \pm \\
0.03 *\end{array}$ & $\begin{array}{l}0.08 \pm \\
0.02 *\end{array}$ & $\begin{array}{c}0.09 \pm \\
0.03 *\end{array}$ & $\begin{array}{c}0.00 \pm \\
0.05^{*}\end{array}$ & 68.18 & 89.36 & 93.33 & 92.38 & 93.57 & 94.27 \\
\hline
\end{tabular}

$(*)$ Indicates statistically significant difference $(\mathrm{P}<0.05)$ from control by the Dunnett's test. 


\section{CONCLUSION}

On the whole, the prepared MFA-DDC based liposomes demonstrate satisfactory stability and reproducibility with high encapsulation efficacy and a sustained drug release profile in slightly acidic media which may enhance the targeting of the inflamed tissues. In addition, MFA-DDC based liposomes caused significant inhibition of paw edema when administrated by oral and intraperitoneal routes of administration. The intraperitoneally administrated MFA-DDC based liposomes were more potent and effective in reducing paw edema in rats than the orally administrated liposomes, suggesting a higher drug bioavailability resulted from the intraperitoneal route of administration. Based on these findings, the bioequivalence studies are recommended to compare the oral bioavailability and the in vivo performance of these liposomes with those of commercially available products of MFA. The present study also suggests further work on other routes of administration (i.e. intravenous and intramuscular) to find out the most appropriate route for clinical applications.

\section{ACKNOWLEDGMENTS}

The authors wish to thank Fundamental Research Grant Scheme from Sports Academy of Universiti Putra Malaysia (Grant \# 5524239) for providing financial support.

\section{REFERENCES}

Abdul Mudalip S, Abu Bakar M, Jamal P, Adam F. Solubility and dissolution thermodynamic data of mefenamic acid crystals in different classes of organic solvents. J Chem Eng Data. 2013;58(12):3447-52.

Alarfaj N, Altamimi S, Almarshady L. Spectrophotometric determination of mefenamic acid in pharmaceutical preparations. Asian J Chem. 2009;21(1):217.

Albanese A. Dystonia: clinical approach. Parkinsonism RelatDisord. 2007;13(Suppl 3):356-61.

Bozzuto G, Molinari A. Liposomes as nanomedical devices. Int J Nanomed. 2015;10(1):975-99.

Brancaccio P, Lippi G, Maffulli N. Biochemical markers of muscular damage. Clin Chem Lab Med. 2010;48(6):757-67.
Chavez L, Leon M, Einav S, Varon J. Beyond muscle destruction: a systematic review of rhabdomyolysis for clinical practice. Critical Care. 2016;20(1):135.

Chen H, Langer R. Oral particulate delivery: status and future trends. Adv Drug Deliv Rev. 1998;34(2):339-50.

Chen M, Vijay V, Shi Q, Liu Z, Fang H, Tong W. FDA-approved drug labeling for the study of drug-induced liver injury. Drug Discov Today. 2011;16(15-16):697-703.

Chiong H, Hakim M, Sulaiman M, Zakaria Z, Zuraini A, Ong $\mathrm{S}$, et al. Development and characterisation study of liposomesencapsulated piroxicam. Int J Drug Deliv. 2011;3(1):64-73.

Chu C, Szoka F. pH-sensitive liposomes. J Liposome Res. 1994;4(1): 361-395.

Cimolai N. The potential and promise of mefenamic acid. Expert Rev Clin Pharmacol. 2013;6(3):289-305.

D'Souza S. A review of in vitro drug release test methods for nano-sized dosage forms. Adv Pharm. 2014;2014:304757.

Dinç E, Yücesoy C, Onur F. Simultaneous spectrophotometric determination of mefenamic acid and paracetamol in a pharmaceutical preparation using ratio spectra derivative spectrophotometry and chemometric methods. J Pharmaceut Biomed. 2002;28(6):1091-100.

Divac N, Prostran M, Jakovcevski I, Cerovac N. Secondgeneration antipsychotics and extrapyramidal adverse effects. BioMed Res Int.2014;2014:656370.

Elorza B, Elorza M, Sainz M, Chantres J. Analysis of the particle size distribution and internal volume of liposomal preparations. J Pharm Sci. 1993;82(11):1160-63.

Elsayed E, Reilly R. Rhabdomyolysis: a review, with emphasis on the pediatric population. PediatrNephrol. 2010;25(1):7-18.

Fehrenbacher J, Vasko M, Duarte D. Models of inflammation: carrageenan-or Complete Freund's Adjuvant (CFA)-induced edema and hypersensitivity in the rat. CurrProtocPharmacol. 2012;5:Unit 5.4.

Fresta M, Villari A, Puglisi G, Cavallaro G. 5-Fluorouracil: various kinds of loaded liposomes: encapsulation efficiency, storage stability and fusogenic properties. Int J Pharm.1993;99(2):145-56. 
Fricker G, Kromp T, Wendel A, Blume A, Zirkel J, Rebmann H, et al. Phospholipids and lipid-based formulations in oral drug delivery. Pharm Res. 2010;27(8):1469-86.

Gatoo M, Naseem S, Arfat M, Mahmood Dar A, Qasim K, Zubair S. Physicochemical properties of nanomaterials: implication in associated toxic manifestations. BioMed Res Int. 2014;2014:498428.

Goh J, Chiong H, Zuraini A, Arifah A, Zakaria Z, Teh L, et al. Rapid spectrophotometric determination, characterization and anti-inflammatory efficacy evaluation of nanoencapsulated diclofenac sodium. J Drug Deliv Sci Technol. 2014;24(4):36166.

Han J, Liu L, Yue X, Chang J, Shi W, Hua Y. A binuclear complex constituted by diethyldithiocarbamate and copper(I) functions as a proteasome activity inhibitor in pancreatic cancer cultures and xenografts. Toxicol Appl Pharmacol. 2013;273(3):477-83.

Imai T, Nohdomi K, Acartürk F, Otagiri M. Enhancement of dissolution and absorption of mefenamic acid by egg albumin. J Pharm Sci. 1991;80(5):484-87.

Kannan V, Balabathula P, ThomaL, Wood G. Effect of sucrose as a lyoprotectant on the integrity of paclitaxel-loaded liposomes during lyophilization. J Liposome Res. 2015; 25(4):270-278.

Kim H, Kim Y, Lee J. Liposomal formulations for enhanced lymphatic drug delivery. Asian J Pharm Sci. 2013;8(2):96-103.

Kunasekaran V, Krishnamoorthy K. Multi criteria decision making to select the best method for the preparation of solid lipid nanoparticles of rasagiline mesylate using analytic hierarchy process. J Adv Pharm Technol Res. 2014;5(3):115.

Lai C, Wang T. Conjugates of dithiocarbamates with pharmacologically active agents and uses therefor. 2002: Google Patents.

Lee S, Lee J, Choi Y. Characterization and evaluation of freeze-dried liposomes loaded with ascorbyl palmitate enabling anti-aging therapy of the skin. Bull Korean Chem Soc. 2007;28(1):99-102.

Martinez-Martinez S, Gomez del Arco P, Armesilla A, Aramburu J, Luo C, Rao A, et al.Blockade of T-cell activation by dithiocarbamates involves novel mechanisms of inhibition of nuclear factor of activated T cells. Mol Cell Biol.1997;17(11):6437-47.
Mo R, Gu Z. Tumor microenvironment and intracellular signalactivated nanomaterials for anticancer drug delivery. Mater Today. 2016;19(5):274-283.

MuÈller R, MaÈder K, Gohla S. Solid lipid nanoparticles (SLN) for controlled drug delivery-a review of the state of the art. Eur J Pharm Biopharm. 2000;50(1):161-77.

Neha Mohan P, Suganthi V, Gowri S. Evaluation of antiinflammatory activity in ethanolic extract of Coriandrum sativum L. using Carrageenan induced paw oedema in albino rats. Der Pharma Chemica. 2013;5(2):139-43.

Ong S, Ming L, Lee K, Yuen K. Influence of the encapsulation efficiency and size of liposome on the oral bioavailability of griseofulvin-loaded liposomes. Pharm. 2016;8(3):25.

Othman N, Awadis L. Spectrophotometric determination of mefenamic acid in pharmaceutical preparations via arsenazo III - cerium (III) reaction. J Raf Sci. 2009;20(1):8-21.

Raike R, Jinnah H, Hess E. Animal models of generalized dystonia. NeuroRx. 2005;2(3):504-12.

Samad A, Sultana Y, Aqil M. Liposomal drug delivery systems: an update review. Curr Drug Deliv. 2007;4(4):297-305.

Sercombe L, Veerati T, Moheimani F, Wu S, Sood A, Hua S. Advances and challenges of liposome assisted drug delivery. Front Pharmacol. 2015;6:286.

Siddiqui M, Alothman Z, Rahman N. Analytical techniques in pharmaceutical analysis: A review. Arab J Chem. 2013;10(Suppl 1):S1409-S21.

Steen K, Steen A, Reeh P. A dominant role of acid $\mathrm{pH}$ in inflammatory excitation and sensitization of nociceptors in rat skin, in vitro. J Neurosci.1995;15(5):3982-9.

Thamphiwatana S, Fu V, Zhu J, Lu D, Gao W, Zhang L. Nanoparticle-stabilized liposomes for $\mathrm{pH}$-responsive gastric drug delivery. Langmuir. 2013;29(39):12228-12233.

Wagner A, Vorauer-Uhl K. Liposome technology for industrial purposes. J Drug Deliv. 2010;2010:591325.

Wehbe M, Anantha M, Backstrom I, Leung A, Chen K, Malhotra A, Bally M. Nanoscale reaction vessels designed for synthesis of copper-drug complexes suitable for preclinical development. PLoS One. 2016;11(4):e0153416. 
Wen M, Farid R, Kassem A. Nano-proniosomes enhancing the transdermal delivery of mefenamic acid. J Liposome Res. 2014;24(4):280-9.

Woodbury D, Richardson E, Grigg A, Welling R, Knudson B. Reducing liposome size with ultrasound: bimodal size distributions. J Liposome Res. 2006;16(1):57-80.
Zhang J, Fan Y, Smith E. Experimental design for the optimization of lipid nanoparticles. J Pharm Sci. 2009;98(5):1813-19.

Received for publication on $06^{\text {th }}$ January 2018 Accepted for publication on 23 ${ }^{\text {th }}$ April 2018 